\title{
Research on Mathematical Model and Cutting Characteristics in Machining of Natural Marble by Diamond Coated Tool
}

\author{
Guangyu YAN*, Yuhou WU**, He WANG***, Dehong ZHAO***, Feng LU**** \\ *Shenyang Jianzhu University, Shenyang 110168, China, E-mail: 775083630@qq.com \\ **Shenyang Jianzhu University, Shenyang 110168, China, E-mail: wuyh@sjzu.edu.cn \\ ***Shenyang Jianzhu University, Shenyang 110168, China, E-mail: 4404992@qq.com \\ ****Shenyang Jianzhu University, Shenyang 110168, China, E-mail: 85755340@qq.com \\ *****Shenyang Jianzhu University, Shenyang 110168, China, E-mail: lufeng72@126.com@qq.com \\ cross $^{\text {ref }}$ http://dx.doi.org/10.5755/j01.mech.25.2.23309
}

\section{Introduction}

Natural marble is widely used in the field of decoration and engineering due to its high compactness, abrasive resistance, and chemical stability [1]. There is a huge consumption in the machining tool on account of the complex brittleness of natural marble. The super-hard cutting tools such as diamond film coating tool are gradually applied in the cutting of hard-brittle material as the high hardness, great abrasion performance, and high cutting precision. In order to maximize the economic performance of diamond tool, the balance between service life and cutting efficiency need to be obtained [2]. Normally, the machinability of cutting tools is directly affected by the tool hardness and abrasion resistance of substrate. However, there are relevant factors such as physical properties, cooling condition, and cutting parameters, may affect the service life and machining characteristics of cutting tools.

The milling process of natural marble is a rapid removal process of stone dense mineral particles substantially. It belongs to cutting dynamic category, which is mainly influenced by cutting parameters include spindle speed, cutting depth, and feed speed. The cutting force and specific cutting energy are two key factors for evaluating the cutting performance of diamond tools and having a great impact on cutting temperature, tool wear, and machining quality of natural stone. According to the empirical model of cutting force and specific cutting energy with machining parameters of natural marble milling by diamond coated tools, there will be of great benefit to stone machining industry, which leads to a deeper understanding of the cutting mechanism and making a better optimization of cutting parameters.

There are few studies on cutting characteristics of natural stone. Huang Guoqin et al. established machining model of diamond beads based on the research of the diameter wear of diamond sintered wire saw for cutting granite [3]. Xu Xipeng et al studied the influence of cutting speed, feed speed, and cutting depth on the cutting force of diamond circular saw blades in the case of sawing the granite [4]. Izzet Karakurt et al. analysed the cutting force acting on diamond sawblade in sawing of granitic rocks [5].

As for the hard-brittle material machining characteristics, Huang Hongwu et al. researched on the grinding force and grinding energy of the engineering ceramics [6]. The results indicated that grinding force of per grit, specific energy corresponding to the maximum undeformed chip thickness well. Hamed Masoumi et al. studied the basic grinding factors such as force ratio, specific material removal rate, maximum undeformed chip thickness, and specific grinding energy of high-velocity oxyfuel thermally sprayed coating using a resin bonded diamond wheel [7]. Buyuksagis and Goktan concluded the sawing energy empirical formula of different natural stone on the base of the cutting experiment of diamond circular saw blades [8]. Sanjay Agarwal and Venkateswara Rao discussed the surface damage formation and material removal mechanisms in $\mathrm{SiC}$ grinding [9]. Chenglong Zhang et al. carried out the rotary ultrasonic machining of brittles [10].

During the material removal of high-efficiency process of natural marble milling by diamond tool, the contact stress of diamond grit on per unit volume is decided by equivalent cutting thickness, which has a great impact on the material removal efficiency and surface quality of workpiece [11]. In this paper, the theoretical analysis and experimental investigation of cutting force and specific energy during the milling process of natural marble were carried out. The mathematical model and empirical equations were established. The cutting characteristics of diamond coated tool and non-coated tool were analysed. The results of this investigation provided reliable evidence for the parameter optimization of the marble machining industry and manufacture of super-hard cutting tool specialized for hard-brittle material.

\section{Experimental study}

2.1. Theoretical model of cutting force and specific energy

In the machining process of natural marble, cutting force and cutting energy are derived from the chip formation, which constraints the machining quality and efficiency.

Fig. 1 shows the material removal procedure of stone particles. The whole material removal process can be divided into two stages when the diamond grits contact with the surface particles of natural stone. First stage, microcracks appear inside the material structure at the beginning of diamond grit sliding on the workpiece surface [12], and then diffuse around the crush area under synthetic impacts of cutting forces from different directions along with the cutting process. Second stage, chip-forming as the material stripping from the surface of natural stone after the cutting cracks extend to the surface, the impact of cyclic stress enables fracture in the crush area which creates chips that flow up along with the flutes on the cutter and wiped out from the cutting area. 


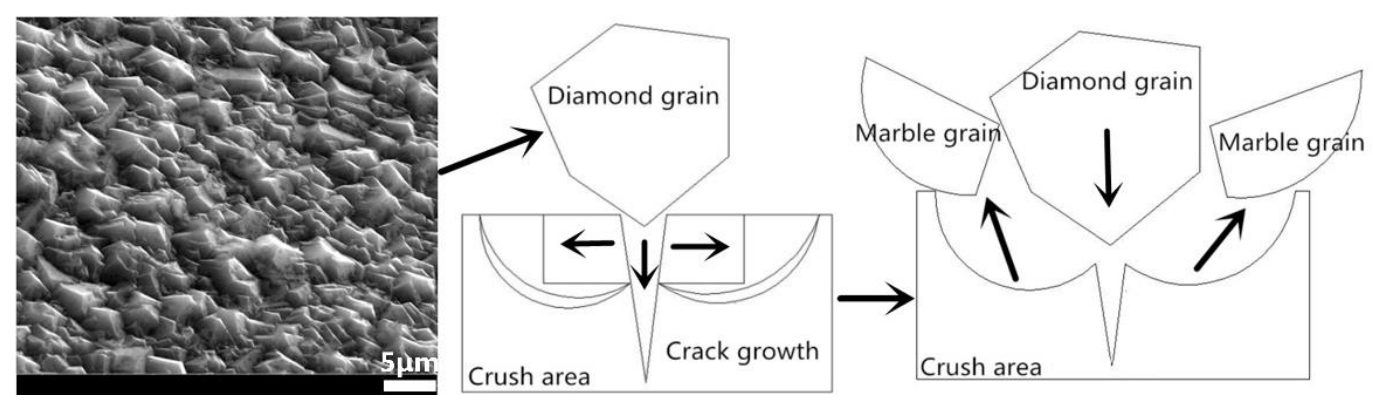

Fig. 1 Diagram of the removal process of natural marble cutting by diamond grits

Contact stress of diamond cutting tool is mainly determined by equivalent chip thickness $[13,14]$. The theoretical chip model of natural stone can be represented by equivalent chip thickness as shown in Fig. 2. The effective cutting area of coated tool can be expressed by the product of radial cutting depth and feed speed, which is the product of cutting speed and actual cutting thickness as well. Therefore, the relationship between equivalent chip thickness and machining parameters can be expressed by the equation as follows:

$$
h=\frac{a_{p} f}{v_{t}},
$$

where: $h$ is equivalent chip thickness, $\mathrm{mm} ; a_{p}$ is radial cutting depth, $\mathrm{mm} ; f$ is feed speed, $\mathrm{mm} / \mathrm{min} ; v_{t}$ is cutting speed, $\mathrm{mm} / \mathrm{min}$.

It can be seen from Eq. (1) that the equivalent chip thickness is related to the cutting depth, feed speed, and cutting speed respectively.

$$
\begin{aligned}
& f_{t}=k_{t} h^{\delta_{t}}, \\
& f_{c}=k_{c} h^{\delta_{c}},
\end{aligned}
$$

where: $f_{t}, f_{c}$ are radial and tangential cutting forces of per diamond grit on cutter contact point respectively, $\mathrm{N} ; k_{t}, k_{c}$ are radial and tangential cutting force coefficients of single diamond grit respectively; $\delta_{t}, \delta_{c}$ are radial and tangential cutting force indexes of single diamond grit respectively.

On the condition of interrupted cutting process, the natural marble material was removed in a brittle regime. The machining stability of cutting tool is affected by the impact of cyclic stress [14].

Structural heterogeneity area exists inside the natural marble, during the interrupted cutting process, irregular radial, and lateral cracks appear on the brittle crack area of natural stone under the effect of periodicity cutting vibration [15], which leads to a disturbance on cutting force.

Therefore, the perturbation coefficients of cutting force under different cutting parameters need to be considered in calculating the radial and tangential cutting forces. The mathematic relation is indicated as follows:

$$
\begin{aligned}
& F_{t}=K_{t} h^{\sigma_{t}}, \\
& F_{c}=K_{c} h^{\sigma_{c}},
\end{aligned}
$$

where: $F_{t}$ is radial cutting force on cutter contact point; $F_{c}$ is tangential cutting force on cutter contact point; $K_{t}, K_{c}$ are radial and tangential force coefficients on cutter contact point respectively; $\sigma_{t}, \sigma_{c}$ are radial and tangential force indexes on cutter contact point respectively.

According to Eqs. (4) and (5), the non-linear relationship between the resultant cutting force and machining parameters can be expressed by power function. Fig. 3 shows the geometrical features between all kinds of cutting forces and machining parameters.

The resultant cutting force of feed direction and axial direction by means of formula:

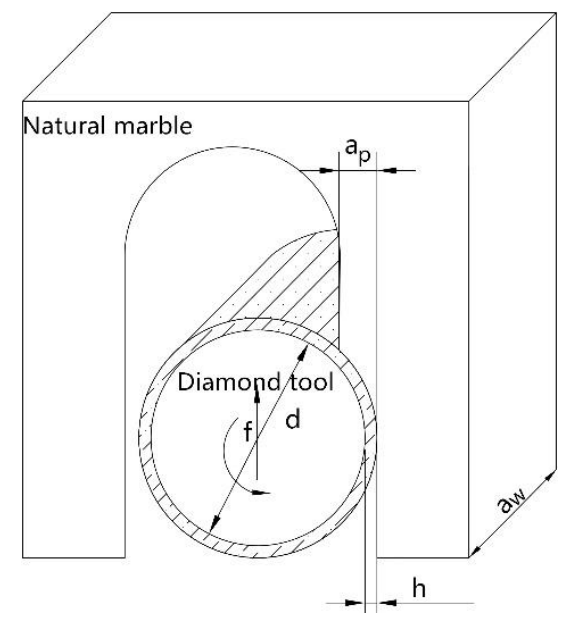

Fig. 2 Diagram of stone machining process

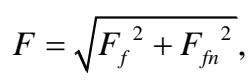

where: $F$ is resultant cutting force between feed direction and axial direction, $\mathrm{N} ; F_{f n}$ is cutting force perpendicular to feed direction, $\mathrm{N} ; F_{f}$ is cutting force of feed direction, $\mathrm{N}$.

The included angle $\alpha$ between resultant force $F$ and feed direction cutting force $F_{f}$ is equal to:

$$
\alpha=\tan ^{-1}\left(\frac{F_{f n}}{F_{f}}\right) .
$$

The contact angle $\theta$ between diamond coated tool and workpiece is calculated as follows:

$$
\theta=\cos ^{-1}\left(1-\frac{2 a_{p}}{d}\right)
$$

where: $d$ is tool diameter, mm.

Based on the contact geometrical relationship of cutter and workpiece, the radial and tangential cutting force 
on the contact point can be expressed by resultant force $F$ :

$$
\begin{aligned}
& F_{c}=F \sin \beta, \\
& F_{t}=F \cos \beta .
\end{aligned}
$$

The included angle $\beta$ between resultant force $F$ and tangential cutting force $F_{c}$ :

$$
\beta=\alpha-N \theta,
$$

where: $N=\frac{B C}{A C}$.

The scaling factor $N$ depends on the location of the application point of the resultant force $F$ on the arc of contact $A C$ between cutter and workpiece. During the experiment, the maximum cutting depth reaches to $2 \mathrm{~mm}$, according to the empirical algorithms based on actual cutting tests [16], the numerical range of $N$ is calculated from 0.48 to 0.52 under different radial cutting depth from 0.2 to $2.0 \mathrm{~mm}$. Therefore, a mean value of 0.5 of $N$ parameter could be adopted in this test.

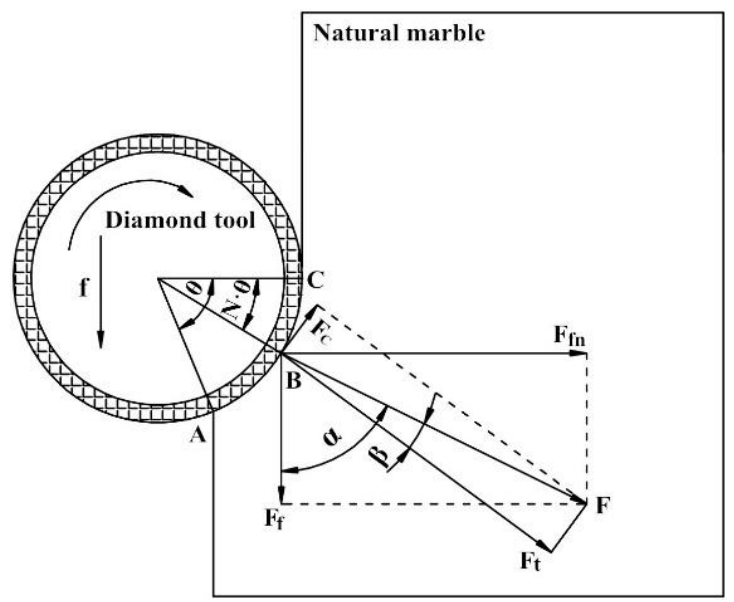

Fig. 3 Diagram of cutting parameters

The cutting energy consumption results from the material removal process under the settled machining factors and cutting forces. Therefore, the specific cutting energy $E$ can be calculated by related cutting parameters:

$$
E=\frac{F_{c} v_{t}}{f a_{p} a_{w}}
$$

The numerator of Eq. (12) is the product of tangential cutting force and cutting speed, the physical significance refers to the energy consumption of cutting system per unit time; the denominator is the product of feed speed, cutting width, and radial cutting depth, the physical significance is the removal volume of workpiece per unit time. As for the same kind of natural stone, the value of specific cutting energy fluctuates in a small scale under the invariability cutting conditions.

Simplifying Eq. (12) with Eqs. (1) and (5) shows that:

$$
E=K_{e} h^{\sigma_{c}-1},
$$

where: $K_{e}=\frac{K_{c}}{\alpha_{w}}$.

According to the analysis on the geometric model of natural stone machining process by diamond milling tool, cutting force $F_{c}, F_{t}$, and specific cutting energy $E$ can be expressed by different values cutting parameters.

\subsection{Theoretical model of cutting force and specific energy}

Fig. 4 shows the cutting experiment platform. The experiment in this paper is carried out by DMG NC milling center. The CVD diamond coated carbide cutter used in the cutting process has a $6 \mathrm{~mm}$ diameter, $60 \mathrm{~mm}$ length, and double edge ball endmill. There is a $5 \mu \mathrm{m}$ diamond film on the surface of cutter and the diamond particle size is around 0.5-1 $\mu \mathrm{m}$. The natural white marbles are chosen for the milling tests, which has a large market demand.

The area of the workpieces applied in the experiment is $50 \times 50 \mathrm{~mm}$ and height is $20 \mathrm{~mm}$. The physical properties of white marble are given in Table 1. It consists mainly of calcium carbonate $\left(\mathrm{CaCO}_{3}\right)$. The cutting forces $F_{f n}$ and $F_{f}$ were measured by Kistler multicomponent dynamometer (9257B). The sampling rate is $1000 \mathrm{~Hz}$ and the sensitivity is $-7.764 \mathrm{pC} / \mathrm{N}$.

In order to investigate the changing characteristics of cutting force and surface roughness along with machining process, cutting tests of CVD diamond tools and non-coated cemented carbide tools milling natural marble were carried out under the fixed machining parameters. Both the cutting processes lasted 200 minutes and the cutting forces were recorded every 20 minutes.

All the machining parameters selected in the tests are within a common range of actual stone processing industry. The axial cutting depth is kept at $3 \mathrm{~mm}$ and the following three milling parameters were distinguished at the following levels as shown in Table 2 and the mean values of three tests were calculated finally.

Physical properties of natural marble

\begin{tabular}{|c|c|c|c|c|c|c|c|}
\hline Properties & $\begin{array}{c}\text { Density, } \\
\mathrm{kg} / \mathrm{m}^{3}\end{array}$ & $\begin{array}{c}\text { Water ab- } \\
\text { sorption, } \%\end{array}$ & $\begin{array}{c}\text { Compressive } \\
\text { strength, MPa }\end{array}$ & $\begin{array}{c}\text { Abrasion re- } \\
\text { sistance } \\
\text { index }\end{array}$ & $\begin{array}{c}\text { Shock } \\
\text { Strength, } \mathrm{cm}\end{array}$ & $\begin{array}{c}\text { Elastic } \\
\text { Modulus, MPa }\end{array}$ & $\begin{array}{c}\text { Moh's } \\
\text { hardness }\end{array}$ \\
\hline White marble & 2705 & 0.24 & 92 & 0.52 & 61 & 75000 & 3 \\
\hline
\end{tabular}

\section{Experimental results and discussions}

\subsection{Effect of cutting parameters on cutting force}

Fig. 5, a and b demonstrate the radial and tangential cutting forces on cutter-contact point increase with the increase of radial cutting depth and feed speed respectively. When the cutting depth increases, more diamond particles involve in the cutting process of natural stone. As the cutting force is the summation of cutting forces of each diamond 
particle contained in the machining, this leads to the increase on the two directions cutting forces.

Table 2

Arrangement of cutting experiment

\begin{tabular}{|c|c|}
\hline Cutting factors & Levels \\
\hline Spindle speed $n, \mathrm{r} / \mathrm{min}$ & 3000 \\
\hline Feed speed $f, \mathrm{~mm} / \mathrm{min}$ & $100 / 200 / 300 / 400 / 500$ \\
\hline \multirow{2}{*}{ Radial cutting depth $a_{\mathrm{p}}, \mathrm{mm}$} & $0.2 / 0.4 / 0.6 / 0.8 / 1.0 /$ \\
& $1.2 / 1.4 / 1.6 / 1.8 / 2.0$ \\
\hline Axial cutting depth $a_{w}, \mathrm{~mm}$ & 3 \\
\hline Repeated time of each test & 3 \\
\hline
\end{tabular}

The curves in Fig. 5 indicate that there is a significant impact of cutting depth on cutting forces in both directions, the value of radial cutting force is obviously larger than tangential cutting force. It is because the radial cutting force is the main cutting force on contact point of diamond cutting tool at the material removal direction.
3.2. Empirical model of cutting force and energy

Figs. 6 and 7 show the regression analysis and equations of cutting force $F_{c}$ and $F_{t}$ with the change of equivalent chip thickness under four different levels of feed speed, respectively.

The cutting force presents an exponential growth with the increase of equivalent chip thickness. According to the coefficients $R^{2}$ of fitting curve under different levels of feed speed, the theoretical models and empirical models based on actual cutting experiment of cutting force and equivalent chip thickness are basically unanimous. In the changing process of machining feed speed around 100$400 \mathrm{~mm} / \mathrm{min}$, the two main cutting forces increase with the increase of equivalent chip thickness, and the value of $F_{\mathrm{c}}$ increases with the increase of feed speed from the maximum $13.36 \mathrm{~N}$ at $100 \mathrm{~mm} / \mathrm{min}$ to the maximum $33.32 \mathrm{~N}$ at $400 \mathrm{~mm} / \mathrm{min}$; the value of $F_{\mathrm{t}}$ increases from the maximum $61.51 \mathrm{~N}$ at $100 \mathrm{~mm} / \mathrm{min}$ to $100.74 \mathrm{~N}$ at $400 \mathrm{~mm} / \mathrm{min}$.

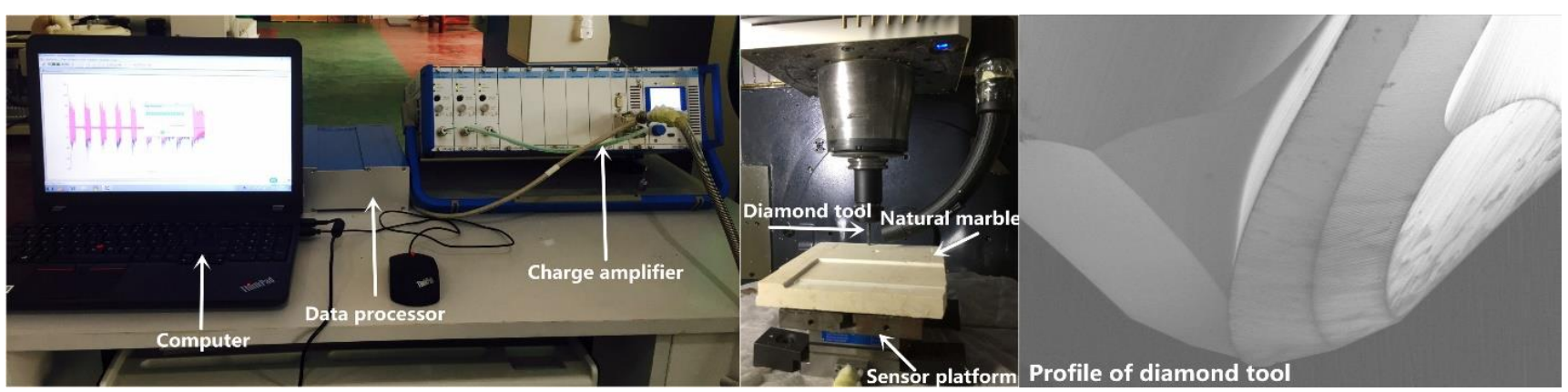

Fig. 4 Machining test platform

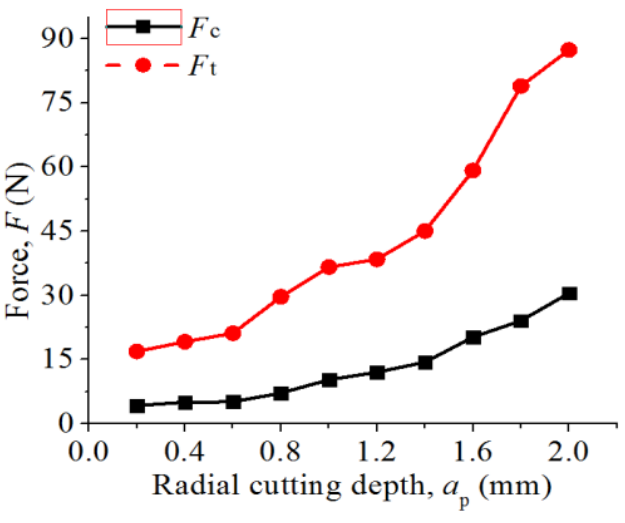

a

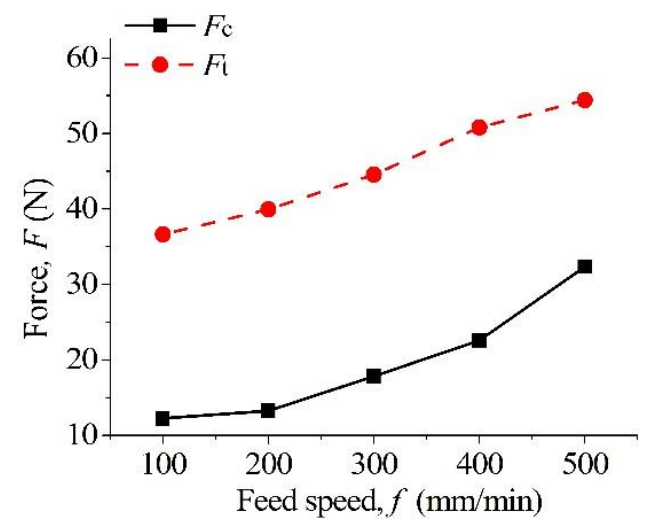

$\mathrm{b}$

Fig. 5 Relationship of cutting parameters and cutting force: $a$ - radial cutting depth, $b$ - feed speed

The material crushing area consists of different size of stone particles existed during the brittle material removal process. The cutting forces are transmitted through the crushing area and the broken stone particles are fritted and inlayed with each other. The machining time of diamond grits on per material crushing area reduces as the feed speed increases, the cracks inside workpiece needs bigger cutting force to extend to the surface in shorter time to achieve material removal efficacy. At last, the resultant cutting force of diamond cutting tool increases.

Fig. 8 shows the curvilinear relationship between specific cutting energy and equivalent chip thickness under four different feed speed from 100 to $400 \mathrm{~mm} / \mathrm{min}$. The coefficients $R^{2}$ of fitting curve indicate goodness of fitting model of specific cutting energy are effective, and the theoretical model is quite consistent with the experimental data.

The specify cutting energy decreases in a power curve with the increase of equivalent chip thickness and it decreases with the increase of feed speed from the maximum $3.983 \mathrm{~J} / \mathrm{mm}^{3}$ at $100 \mathrm{~mm} / \mathrm{min}$ to the maximum $2.324 \mathrm{~J} / \mathrm{mm}^{3}$ at $400 \mathrm{~mm} / \mathrm{min}$. It can be seen in Fig. 3 that the contact angle $\theta$ is inversely proportional to the radial cutting depth $a p$, and it has the same relationship with equivalent chip thickness from Eq. (1). The energy consumption in grinding process mainly includes the material plastic deformation, friction, chip kinetic energy and crushing energy. The increase of equivalent chip thickness and feed speed leading to the increase of effective cutting area. The contact length of cutting blade and workpiece were magnified. The 
increase of the volume of the removing material has the main influence on the decrease of the specific energy, as the specific energy is an energy required to remove a unit volume of the workpiece material.

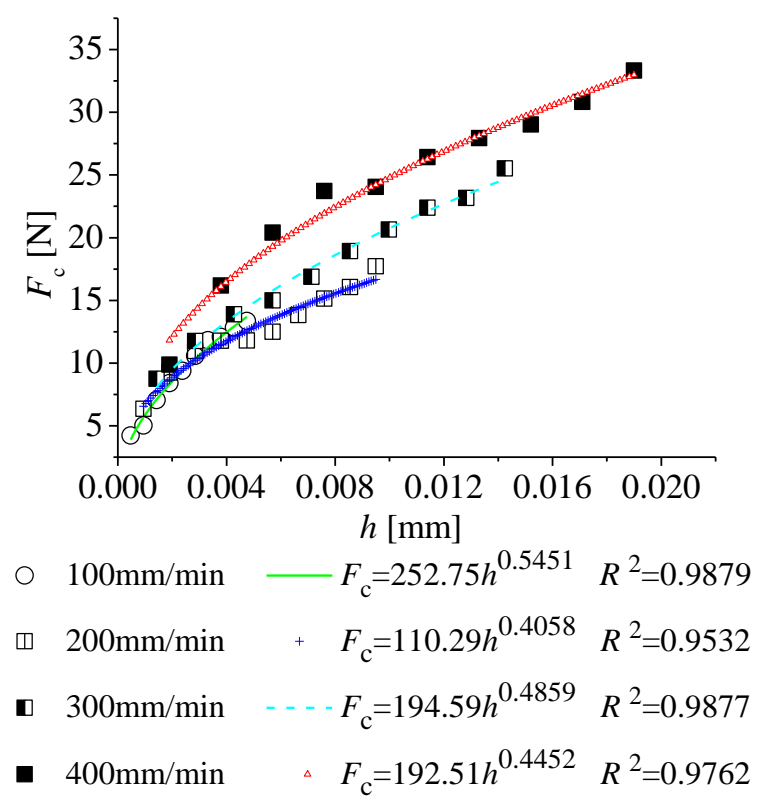

Fig. 6 Fitting curve and equations of tangential cutting force $F_{\text {c }}$ and equivalent chip thickness $h$

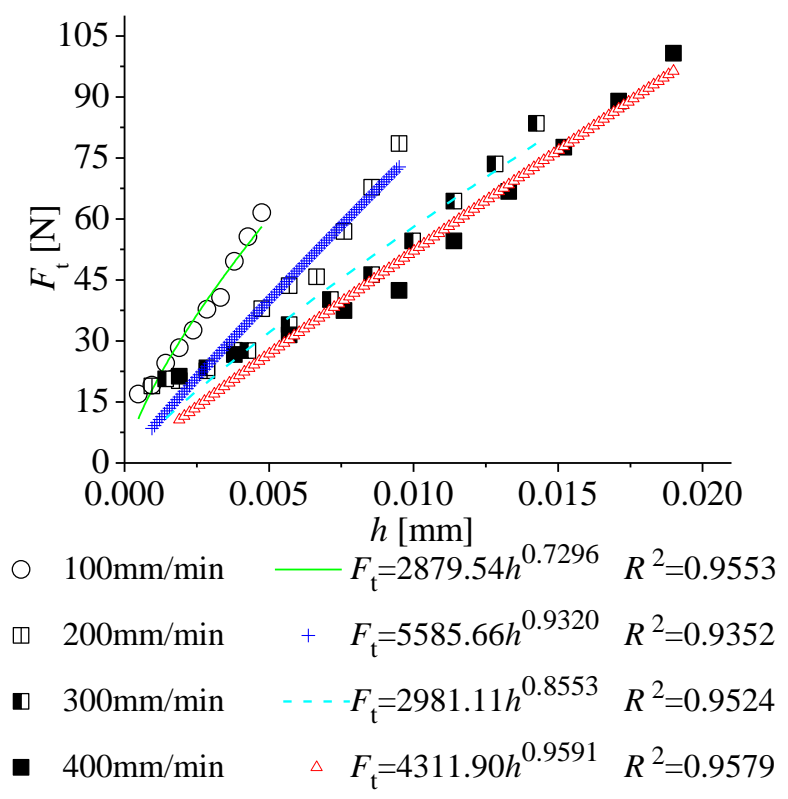

Fig. 7 Fitting curve and equations of radial cutting force $F_{c}$ and equivalent chip thickness $h$

Fig. 9 shows the SEM picture of the natural marble surface after machined by diamond tool, there are obvious brittle fracture scratches region. During the removal process of natural marble, hard particles on the surface of workpiece will cause destructive brittleness removal and a certain amount of cutting energy is consumed during that period. As the feed speed increases, part of the particles would be excreted. Therefore, there would be a decrease of energy consumption by increasing feed speed of natural marble machining.

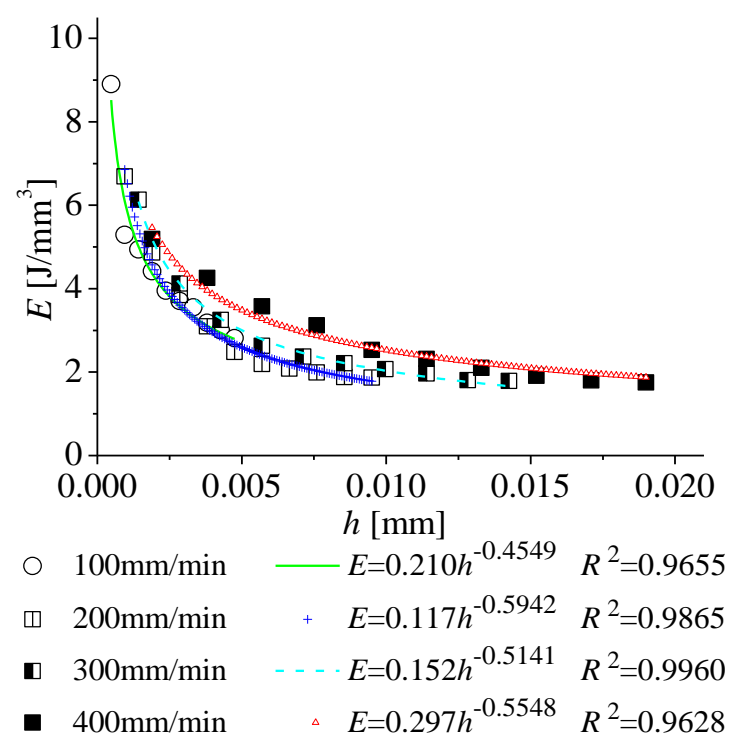

Fig. 8 Fitting curve and equations of specific cutting energy $E$ and equivalent chip thickness $h$

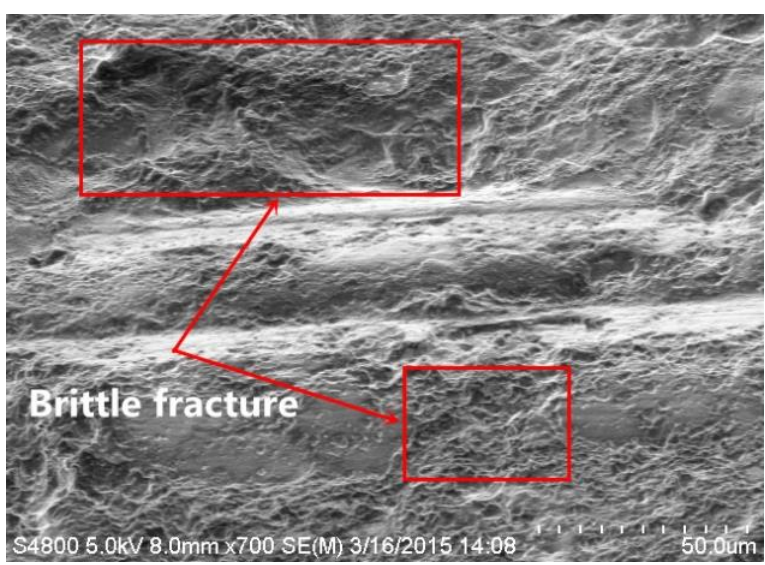

Fig. 9 SEM pictures of the natural marble surface after machined by diamond tool

\subsection{Cutting characteristics}

Fig. 10 shows the relationship of cutting time and cutting force/surface roughness of natural marble. There are four cutting stages during the cutting process of the coated and non-coated cemented carbide tool.

1. The first stage: As Fig. 10, a shows, during the $O A$ period (20-60 min), there is slight fluctuation on the cutting force of diamond coated tool and the surface roughness increases from 0.482 to $0.519 \mu \mathrm{m}$; In the $O_{1} A_{1}$ period of Fig. $10, \mathrm{~b}$, the first cutting steady stage of non-coated tool lasts only 20 minutes and during 40-60 min, there is an increase on the value of cutting forces and surface roughness and fluctuated in a large range. This stage belongs running in period;

2. The second stage: The cutting force and surface roughness of natural marble in both of $A B$ and $A_{1} B_{1}$ periods of two types of cutting tools increase smooth and steady along with the machining process. This is the stable cutting region. But the $A_{1} B_{1}$ only lasts 40 minutes compared with 80 minutes of $\mathrm{AB}$ period of the diamond coated tool.

3. The third stage: In this stage, the cutting force increases with the increase of cutting time, the surface roughness in $B C$ period keeps a stable level. However, the roughness during $B_{1} C_{1}$ increases from 1.256 to $1.602 \mu \mathrm{m}$; 
4. The last stage: This is the last stage in the 200 minutes cutting process. The increase trend of cutting force and surface roughness is intensified and the value of $R a$ of

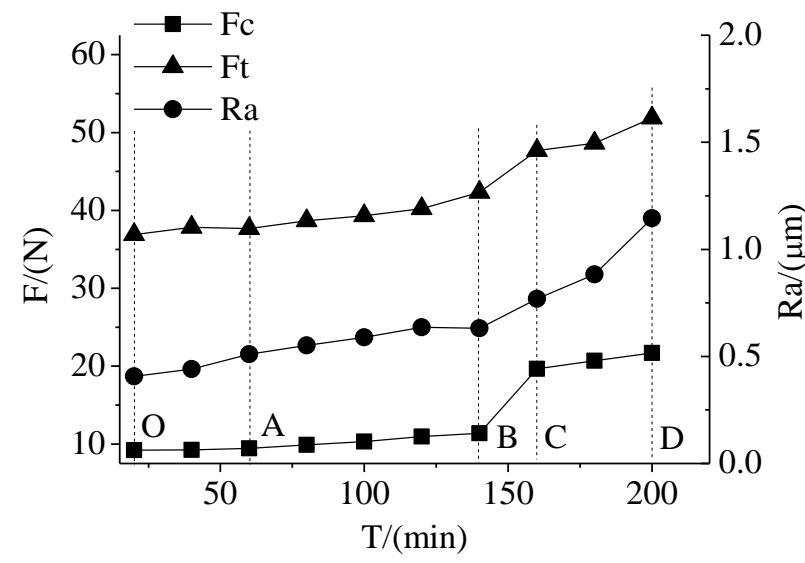

a non-coated tool reaches $2.5 \mu \mathrm{m}$ that cannot meet the machining requirements of natural marble.

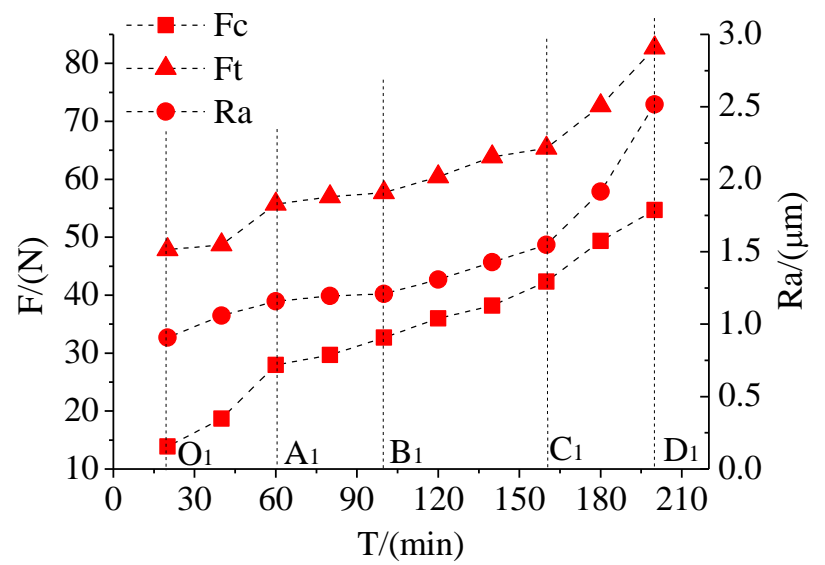

b

Fig. 10 Relationship of cutting time and cutting force/surface roughness of workpiece $(n=5000 \mathrm{r} / \mathrm{min}, f=300 \mathrm{~mm} / \mathrm{min}$, $\left.a_{p}=1 \mathrm{~mm}, a_{w}=3 \mathrm{~mm}\right): \mathrm{a}$ - diamond coated cemented carbide tool, $\mathrm{b}$ - non-coated cemented carbide tool

\section{Conclusions}

The machining characteristics of natural marble milling were researched for extending the material removal mechanism involved in the hard-brittle milling process. Reliability of mathematical models of cutting force and specific cutting energy were verified by the regression analysis based on experimental data. The following conclusions can be drawn:

1. Specific cutting energy in the machining of natural marble can be expressed by the main cutting force and equivalent chip thickness through a mathematic model.

2. According to the experimental results of milling tests, the radial and tangential cutting forces of cutter contact point increase with the increase of radial cutting depth and feed speed.

3. The increase of feed speed and equivalent chip thickness resulting in the decline of friction coefficient between tool and workpiece and then leading to the decrease of specific cutting energy.

4. Machining process of natural marble can be divided into four stages include running-in stage, stable stage, interim stage and aggravate stage. There is a large advantage on the diamond coated tool compared with the non-coated tool.

\section{Acknowledgement}

This research received financial support from the Liaoning Natural Science Foundation (20170540757); the Scientific and Technological Transformative Project of Shenyang (Z18-5-023).

\section{References}

1. Wu, Y. H.; Zhao, D. H. 2011. Special-shaped stone machining equipment and technology, Beijing, Science Press, pp. 1-7.

2. Aslantas, K.; Özbek, O.; Ucun, İ.; Büyüksağ [idot] ş, I. S. 2009. Investigation of the effect of axial cutting force on circular diamond sawblade used in marble cutting process, Materials and Manufacturing Processes
24(12): 1423-1430.

https://doi.org/10.1080/10426910903344039.

3. Huang, G. Q.; Huang, H.; Guo, H.; Xu X. P. 2009. Influences of sawing parameters on forces and energy in wire sawing of granite, Journal of Mechanical Engineering 43(3): 234-239. https://doi.org/10.3901/JME.2009.03.234.

4. Xu, X.; Li, Y.; Yu, Y. 2003. Force ratio in the circular sawing of granites with a diamond segmented blade, Journal of Materials Processing Technology 139(1-3): 281-285. https://doi.org/10.1016/S0924-0136(03)00236-X.

5. Karakurt, I.; Aydin, G.; Aydiner, K. 2013. Experimental and statistical analysis of cutting force acting on diamond sawblade in sawing of granitic rocks, Proceedings of the Institution of Mechanical Engineers, Part B: Journal of Engineering Manufacture 227(2): 286-300. https://doi.org/10.1177/0954405412460971.

6. Han, X. G.; H. H. H.; Wanli, S. X.; MI H. X. 2007. Experimental investigations of advanced ceramics in high efficiency deep grinding, Chinese Journal of Mechanical Engineering 1, 030. https://doi.org/10.3901/JME.2007.01.176.

7. Masoumi, H.; Safavi, S. M.; Salehi, M. 2014. Grinding force, specific energy and material removal mechanism in grinding of HVOF-sprayed $\mathrm{WC}-\mathrm{Co}-\mathrm{Cr}$ coating, Materials and Manufacturing Processes 29(3): 321-330. https://doi.org/10.1080/10426914.2013.872261.

8. Buyuksagis, I. S.; Goktan, R. M. 2005. Investigation of marble machining performance using an instrumented block-cutter, Journal of Materials Processing Technology 169(2): 258-262. https://doi.org/10.1016/j.jmatprotec.2005.03.014.

9. Agarwal, S.; Rao, P. V. 2008. Experimental investigation of surface/subsurface damage formation and material removal mechanisms in $\mathrm{SiC}$ grinding, International Journal of Machine Tools and Manufacture 48(6): 698710 . https://doi.org/10.1016/j.ijmachtools.2007.10.013.

10. Zhang, C.; Zhang, J.; Feng, P. 2013. Mathematical model for cutting force in rotary ultrasonic face milling 
of brittle materials, The International Journal of Advanced Manufacturing Technology 69(1-4): 161-170. https://doi.org/10.1007/s00170-013-5004-z.

11. Durgumahanti, U. P.; Singh, V.; Rao, P. V. 2010. A new model for grinding force prediction and analysis, International Journal of Machine Tools and Manufacture 50(3): 231-240.

https://doi.org/10.1016/j.ijmachtools.2009.12.004.

12. Nakamura, M.; Sumomogi, T.; Endo, T. 2003. Evaluation of surface and subsurface cracks on nano-scale machined brittle materials by scanning force microscope and scanning laser microscope, Surface and Coatings Technology 169: 743-747. https://doi.org/10.1016/S0257-8972(03)00133-6.

13. Sinclair, J. E. 1975. The influence of the interatomic force law and of kinks on the propagation of brittle cracks, Philosophical Magazine 31(3): 647-671. https://doi.org/10.1080/14786437508226544.

14. Kalita, P.; Malshe, A. P.; Kumar, S. A.; Yoganath, V. G.; Gurumurthy, T. 2012. Study of specific energy and friction coefficient in minimum quantity lubrication grinding using oil-based nanolubricants, Journal of Manufacturing Processes 14(2): 160-166. https://doi.org/10.1016/j.jmapro.2012.01.001.

15. Lawn, B.; Wilshaw, T. R. 2010. Fracture of brittle solids. Cambridge university press, pp. 95-108.

16. Hwang, T. W.; Malkin, S. 1999. Grinding mechanisms and energy balance for ceramics, Journal of manufacturing science and engineering 121(4): 623-631. https://doi.org/10.1115/1.2833081.
G. Yan, Y. Wu, H. Wang, D. Zhao, F. Lu

RESEARCH ON MATHEMATICAL MODEL AND CUTTING CHARACTERISTICS IN MACHINING OF NATURAL MARBLE BY DIAMOND COATED TOOL

S u m m a r y

The material removal process of natural marble milling by diamond coated tool is essentially a crack propagation process. The complex brittle machining characteristics remains to be a problem for the hard-brittle material processing industry. In this investigation, the relationships among cutting forces, specific energy and machining parameters were built based on the tool-workpiece contact geometry. Empirical equations of cutting forces and specific energy based on experimental data were established. Changing characteristics of cutting force and surface roughness of natural marble machined by diamond tool and non-coated tool were analyzed. Results demonstrate that the mathematical model of cutting force and specific cutting energy were reliable according to the regression analysis base d on experimental data. Energy consumption during the milling process of natural marble is mainly derived from rubbing action between cutting tool and workpiece. The specific energy decreases with the increase of feed speed and equivalent chip thickness. The machining quality is influenced by cutting force directly. Cutting process can be divided into four stages and there are significant advantages of diamond coated tool in the machining of natural marble compared with the non-coated cemented carbide tool.

Keywords: diamond coated tool; natural marble; cutting force and energy; chip thickness; surface roughness.

Received September 03, 2018

Accepted April 25, 2019 